\title{
A EVOLUÇÃO DA MÃO DE OBRA FEMININA: UMA ANÁLISE ENTRE O ESTADO DO PARANÁ E A CIDADE DE GUARAPUAVA
}

\author{
Emanuele Ferreira* \\ Elisiane Aparecida Antoniazzi ${ }^{\star *}$ \\ Maricléia Aparecida Leite Novak ${ }^{* *}$
}

Resumo: Esta pesquisa aborda a inserção da mão de obra feminina no mercado de trabalho formal. Neste contexto, objetivou-se neste trabalho evidenciar a evolução do mercado de trabalho feminino no Paraná e Guarapuava, o perfil etário e educacional das mulheres inseridas no mercado de trabalho formal e a remuneração média no período de 2010 a 2014. Para a condução desta pesquisa utilizou-se o método dedutivo, comparativo e a pesquisa descritiva. Os resultados obtidos evidenciam a evolução da força de trabalho feminina no Paraná e em Guarapuava, mostram ainda que as mulheres foram em busca de mais qualificação e hoje podem considerar muitos obstáculos superados, entretanto a discriminação e preconceito perduram, principalmente no que diz respeito à remuneração, há um longo caminho a se percorrer para chegar à equidade de gênero no âmbito profissional.

Palavras-chave: Mercado de trabalho, regulamentação, inclusão, gênero feminino.

Abstract: This research addresses the insertion of female labor in the formal labor market. In this context, the objective of this study was to highlight the evolution of the female labor market in Paraná and Guarapuava, the age and educational profile of women entering the formal labor market and the average earnings in the period from 2010 to 2014. For the conduction of this research the deductive, comparative and descriptive methods were used. The results show the evolution of the female labor force in Paraná and Guarapuava, also show that the women went in search of more qualification and today they can consider many obstacles overcome, however the discrimination and prejudice continue, mainly with respect to the remuneration, there is a long way to go to reach gender equity in the professional arena

Keywords: Labor market, regulation, inclusion, female gender.

\footnotetext{
* Universidade Estadual do Centro Oeste- UNICENTRO.

** Possui graduação em CIÊNCIAS ECONÔMICAS pela Universidade Estadual do Centro-Oeste UNICENTRO. Possui mestrado em DESENVOLVIMENTO REGIONAL E AGRONEGÓCIO pela Universidade Estadual do Oeste - UNIOESTE.

*** Bacharel em Ciências Contábeis pela Universidade Estadual do Centro-Oeste - UNICENTRO (2013). Especialista em Auditoria e Controladoria pela UNICESUMAR (2015). Mestre em Desenvolvimento Comunitário pela Universidade Estadual do Centro-Oeste - UNICENTRO.
} 


\section{Introdução}

A inserção das mulheres no mercado de trabalho sempre foi uma tarefa difícil, a sociedade impunha que o sustento da família deveria ser feito pelo marido, e as mulheres viúvas ou solteiras poderiam exercer atividades artesanais desde que no âmbito doméstico, as atividades exercidas pela classe feminina eram desvalorizadas.

Porém, com a evolução do sistema capitalista, as mulheres foram ganhando espaço e durante a revolução industrial no século XVIII elas começaram a trabalhar nas fábricas e passaram a competir no mercado de trabalho juntamente com os homens. Contudo, sua mão de obra continuava desvalorizada sem contar que a carga horária de trabalho era excessiva e as condições de trabalho precárias.

No Brasil, com a Revolução de 1930, a era dos direitos trabalhistas começaria através do presidente Getúlio Vargas. Após um estudo do trabalho feminino feito pelo então ministro Lindolfo Collor, foi expedido o Decreto no $24.417-A$ de 17 de maio de 1932, a primeira lei que versava sobre a situação da mulher trabalhadora e a protegia contra a exploração social.

Desde então, mesmo com a desvalorização da mão de obra feminina no mercado de trabalho em alguns setores, a participação das mulheres é crescente no âmbito profissional e compõem cada vez mais a renda familiar juntamente com o homem contribuindo para o desenvolvimento econômico.

Apesar das diversas dificuldades enfrentadas pelas mulheres para se consolidar no mercado de trabalho e para ter o reconhecimento profissional e a remuneração condizente com suas qualificações, o mercado de trabalho formal tem evoluído na absorção de mão de obra feminina e este trabalho buscar-se-á evidenciar isto através de uma análise estatística descritiva de dados secundários.

Com base em um levantamento de dados secundários juntos ao Instituto Brasileiro de Geografia e Estatística (IBGE) e na Relação Anual das Informações Sociais (RAIS). Acredita-se que houve uma maior entrada do sexo feminino no mercado de trabalho devido abertura comercial, melhores benefícios trabalhistas, maior qualificação feminina e maior busca de independência financeira. Outro fator que pode ter contribuído para a inserção das mulheres no mercado de trabalho foi à busca de proporcionar melhor qualidade de vida para suas famílias.

Este trabalho tem por objetivo verificar a evolução da mão de obra feminina em uma análise comparativa no Estado Paraná e no município de Guarapuava no período de 2010 a 2014, assim como identificar a representatividade das mulheres no mercado de trabalho formal, qual o grupo de setor que mais contrata mão de obra feminina, o nível de escolaridade e a média salarial das mulheres em relação aos homens. 
Ao longo dos anos o mercado de trabalho tem requisitado mais mão de obra feminina para exercer funções com atividades minuciosas e o gênero feminino no mercado de trabalho tem atendido esta demanda muito bem. Em virtude disso, está em constante expansão a participação das mulheres no mercado de trabalho.

Este trabalho está estruturado em cinco capítulos. O primeiro capítulo, separado por seção, são abordadas as teorias relacionadas ao trabalho e ao salário pelos principais pensadores econômicos, Adam Smith, David Ricardo, Karl Marx e Keynes, a Teoria do Capital Humano, a Teoria da Segmentação e a evolução da legislação trabalhista. No terceiro capítulo será detalhada a metodologia utilizada para desenvolver esta pesquisa. No quarto capítulo serão abordados o cenário atual do mercado de trabalho brasileiro do gênero feminino, o perfil socioeconômico do Paraná e de Guarapuava. O quinto capítulo sumariza os temas tratados nos capítulos anteriores e ratifica a relevância deste estudo.

\section{Fundamentação teórica}

O arcabouço teórico desta pesquisa será centrado no mercado de trabalho e na mão de obra, notadamente feminina. Partindo sua análise de quatro grandes pensadores econômicos: Adam Smith, David Ricardo, Karl Marx e John M. Keynes. Além de complementar a discussão com a Teoria do Capital Humano e da Segmentação do Mercado de Trabalho.

\subsection{Teoria salarial}

\subsubsection{Adam Smith}

Desde o século XVIII, quando Adam Smith faz menção ao termo mercado de trabalho, ele traduz que assim como os demais mercados, o mercado de trabalho é regido pela oferta e demanda de trabalho. A oferta de mão de obra se dá em virtude da necessidade de bem-estar do indivíduo para conseguir adquirir bens, assim como desfrutar do lazer, já a demanda por mão de obra ocorre através do objetivo das empresas em alcançarem o máximo de lucro (BRÉMOND e GÉLÉDAN, 1984).

Quando a remuneração do trabalhador é generosa, esta condição possibilitará cuidar melhor de seus filhos, ampliando os limites de multiplicação da espécie; Afinal "toda espécie animal multiplica-se naturalmente em proporção aos meios de que dispõe para sua subsistência” (SMITH, 1996, p. 129). 
Segundo Smith (1996), é fato que quando o trabalhador é mais bem remunerado, este procura doar-se ao máximo em suas atividades laborais, e tende a render muito melhor para os negócios de seu patrão, pois tem o estímulo de progredir na empresa e receber salários altos.

O crescimento vegetativo da população está intimamente ligado aos níveis salariais, pois uma vez aumentando o número de trabalhadores ativos ofertantes de mão de obra forçam os salários pra baixo do nível de subsistência, ao passo que na sequência estas famílias vivendo com níveis salários baixíssimos não terão condições de ter filhos que cheguem à idade produtiva, levando no longo prazo a uma escassez de mão de obra, elevando novamente os níveis salariais, criando um "ciclo vicioso" (BRUE, 2011).

$\mathrm{Na}$ teoria salarial de Smith, chega-se a conclusão de que dois fatores interferem diretamente nos níveis salariais de equilíbrio, de um lado está o crescimento do estoque de capital do patrão que decide investir o excedente em contratação de mais mão de obra e as taxas de crescimento vegetativo da população que interfere na oferta de trabalhadores ativos (SMITH, 1996).

\subsubsection{David Ricardo}

David Ricardo inicia sua abordagem no campo de discussão da sua obra mestra Os Princípios de Economia Politica e Tributação, divergindo da ideia trazida por Adam Smith na obra Uma Investigação sobre as Causas da Riqueza das Nações, a qual ele estudou fielmente para então partir para uma proposta além dos estudos feitos por Smith.

Para Ricardo ao contrário do que diz Smith, existe diferença entre trabalho incorporado e comandado, o trabalho incorporado é invariável; nele está o verdadeiro fundamento do valor e o trabalho comandado varia de acordo com a oferta e demanda (FEIJÓ, 2007).

Para Ricardo não somente a quantidade de trabalho deveria ser calculada para atribuir valor a uma mercadoria, mas também o trabalho necessário para confeccionar os equipamentos necessários para produzir aquela mercadoria. A redução da quantidade de trabalho para produzir algo irá sempre reduzir o valor relativo, e este valor não poderia ser mudado pelos salários.

Se houve algum aumento nos salários de uma dada produção, isto não quer dizer que houve aumento de trabalho; e sim que o trabalhador será mais bem remunerado para executar suas atividades. Haverá aumento ou redução no valor comparativo de uma mercadoria quando a quantidade de trabalho sofrer alteração. 


\subsubsection{Karl Marx}

Na visão de Karl Marx, quando o mercado de trabalho se apresenta na visão dos clássicos trata-se de exploração dos trabalhadores, e ele incorpora o termo mais valia na economia, defendendo que mesmo recebendo um salário de subsistência para executar suas atividades o trabalhador agrega mais trabalho do que recebe em salário gerando um excedente ao seu empregador, esse excedente caracteriza o conceito de mais valia.

Sob está ótica o mercado de trabalho é desigual uma vez que os trabalhadores se tornam refém das organizações, pois elas definem o quanto o trabalhador vai receber sem abrir negociações (BRÉMOND e GÉLÉDAN, 1984).

De acordo com Feijó (2007), Marx separa o trabalho em dois tipos, o trabalho útil e o trabalho abstrato; no primeiro cria-se valor de uso ou utilidade e no segundo cria-se valor ou valor de troca, este é medido pelo tempo de trabalho social dentro dos níveis médios de habilidades.

Em resumo o autor acima citado, conclui que mesmo o trabalho sendo o elemento singular que todas as mercadorias possuem, estas tem seu valor em uma medida de aceite geral, o dinheiro que é o desdobramento simples da forma mercadoria.

O mercado de trabalho para Marx funciona de forma que o trabalhador vende sua força de trabalho e o empregador a compra, aquela força de trabalho em potencial torna-se ativa a partir do momento que se é contratada para trabalhar (MARX 1996).

\subsubsection{John Maynard Keynes}

Para Keynes, a demanda por mão de obra das empresas não está relacionada aos salários e sim a demanda que a empresa pretende atender com sua produção, as quantidades de mão de obra demandadas são definidas fora do equilíbrio do modelo de mercado de trabalho, defendido pelos neoclássicos e o nível de oferta de emprego pode ser inferior à disponibilidade de mão de obra (SINGER, 1979).

Keynes (1996) critica a teoria dos clássicos em relação aos salários, quanto à questão de que quando há fluidez o sistema econômico se autorregulava e quando há rigidez se explicava pelos desajustamentos.

Para os neoclássicos haveria desemprego involuntário somente quando o empregado aceitasse a trabalhar em troca de salário igual ao seu valor marginal, mas mesmo assim não conseguisse encontrar trabalho caso contrário todas as demais situações caracterizavam-se como desemprego voluntário (HUNT 1981). 
Em relação à baixa dos salários nominais, Keynes afirma que alguns economistas defendem que essa queda não irá interferir na demanda agregada, visto que uma vez reduzido os custos das empresas com salários, torna-se possível baixar os preços de algumas mercadorias. Os trabalhadores mesmo com seus salários reduzidos podem ter sua demanda agregada aumentada, a menos que a baixa dos salários desestimule a procura por trabalho, ou seja, a elasticidade da demanda de mão-de-obra seja inferior à unidade (KEYNES, 1996).

\subsection{Teoria do capital humano}

Segundo Lima (1980), para os economistas clássicos a determinação dos salários estava ligada diretamente a quantidade de mão de obra ofertada no mercado, ou seja, em momento de excesso de oferta de mão de obra os salários tenderiam a ser menores e em momento de escassez os salários se recuperariam e subiriam, e considerava-se que toda mão de obra era homogênea e o mercado de trabalho encontraria o equilíbrio assim como os demais mercados existentes na economia.

O mesmo autor segue dizendo, que os clássicos admitiam disparidades salariais e que existiam diferentes qualidades de mão de obra, mas se davam por satisfeitos com uma rápida explicação a respeito, e reduziam a complexidade da heterogeneidade de mão de obra ao encontro das curvas de oferta e demanda.

Com esta ideia de heterogeneidade pode-se dizer que essa explicação simples e superficial realizada pelos clássicos é ineficiente uma vez que é de conhecimento que para diferentes qualidades de trabalho a remuneração de fato também será diferenciada.

Nesse contexto nas décadas de 1950 e 1960, que é incorporada a Teoria do Capital Humano à teoria econômica como é conhecida hoje, que tem por precursores os economistas Mincer (1958), Schultz $(1964,1973,1987)$ e Becker $(1964,1993)$.

Schultz (1973 apud Kelniar 2013, p. 03), "coloca o conhecimento como forma de capital e a decisão de investir na capacitação do trabalhador passam a ser uma deliberação individual ou das partes interessadas em melhorar e/ou aumentar a produtividade". Schultz partiu do pressuposto que o investimento em educação faria do funcionário da empresa um colaborador e que este ampliaria a produtividade na sua rotina de trabalho.

Em síntese a Teoria do Capital Humano trata-se do desenvolvimento das habilidades cognitivas dos indivíduos que a partir delas poderão almejar melhores cargos bem como melhores salários e que o desenvolvimento dessas habilidades se da por meio de investimento na educação. 


\subsection{Teoria da segmentação do mercado de trabalho}

A Teoria da Segmentação do Mercado de Trabalho evidencia que cada tipo de emprego possui critérios diferentes na condução dos processos de admissão, desenvolvimento e promoção dos colaboradores, da mesma forma que apresenta politicas distintas no que diz respeito à coordenação, meios de trabalho e remuneração (SOUZA, 1978).

Os segmentos do mercado de trabalho são denominados de mercado primárioé aquele que o trabalhador possui estabilidade e melhores salários e mercado secundário possui alta rotatividade, baixos salários e más condições de trabalho (LIMA1980).

Segundo Cacciamali (1978) apud Casari (2012), há três frentes teóricas que explicam a existência da segmentação do mercado de trabalho, representadas pelos seguintes autores e suas respectivas justificativas: (DOERINGER; PIORE, 1971) o ajuste alocativo; (VIETORIZ;HARRISON, 1973) o dualismo tecnológico; (REICH; GORDON; EDWARDS, 1973) a estratificação dos trabalhadores.

Em síntese as três teorias se complementam, visto que o desenvolvimento industrial capitalista gera a segmentação, que geram os comportamentos diferenciados dos trabalhadores, que na maioria das vezes estão imutáveis diante das barreiras erguidas entre os mercados de trabalho, e os trabalhadores que fazem parte do secundário estão presos nele e não conseguem progredir para o mercado de trabalho primário. Desta forma o sistema capitalista se fortalece sendo sustentado pela segmentação do mercado de trabalho (LIMA, 1980).

\subsection{Leis trabalhistas voltadas ao gênero feminino no brasil}

\subsubsection{Uma retrospectiva até a Consolidação das Leis Trabalhistas (CLT)}

Ao longo do tempo ocorreram muitas mudanças judiciais que regulamentaram o trabalho do gênero feminino. As mulheres levaram anos para conquistarem seus direitos jurídicos e civis, e esse processo se deu de forma lenta e permanece evoluindo até os dias de hoje.

A primeira lei de proteção à mulher nas indústrias no Brasil foi instituída no estado de São Paulo pela Lei n. ${ }^{\circ} 1.596$ de 29 de dezembro de 1917, onde foi reorganizado o Serviço Sanitário do Estado e beneficiou as mulheres conforme o artigo 94 . $\$$ 5. "Os menores até a idade de 18 anos e as mulheres não poderão, em caso algum, executar nas fábricas serviços noturnos." E o artigo 95. "As mulheres, durante o ulti- 
mo mês de gravidez e o primeiro do puerpério, não poderão trabalhar em quaisquer estabelecimentos industriais".

No ano de 1919 foi criada Organização Internacional do Trabalho (OIT) que teve por objetivo principal a justiça social. As primeiras convenções ocorreram no ano de criação da OIT, são elas as convenções de n. 3 e 4 que tinham como titulo respectivamente "Convenção relativa ao Emprego das Mulheres antes e depois do parto (Proteção à Maternidade)" e "Convenção relativa ao Trabalho Noturno das Mulheres".

Em âmbito federal é aprovado o Decreto n. ${ }^{\circ} 16.300$, de 21 de dezembro de 1923, conforme Calil (2007), expõe: "Facultava às mulheres, empregadas em indústrias e comércios, descanso de trinta dias antes e outros trinta dias mais após o parto" (CALIL, 2007) ${ }^{1}$.

Infelizmente não há como comprovar que as medidas previstas no decreto n. 16.300 foram cumpridas pelas empresas, e pela época leva-se a crer que em sua maioria não foi respeitado.

Deste modo, tanto em âmbito federal e mundial, um fato é evidente a igualdade que se buscava estava cada vez mais longe e com estas medidas não existia proteção e sim proibição, o que se justificava apenas era os benefícios à maternidade que de fato eram imprescindíveis.

Outro marco importante na "Revolução das Mulheres" foi à conquista do voto que no Brasil se deu inicialmente em 1930 embora não obrigatório e em 1932 através do Decreto n. 21.076 aprovado por Getúlio Vargas no Código Brasileiro ficou estabelecido que seria considerado eleitor o cidadão maior de 21 anos sem distinção de sexo, desta forma a mulher conquista o direito de votar e ser votada.

\subsubsection{A Consolidação das Leis Trabalhistas (CLT) voltada ao trabalho das Mulheres}

A Consolidação das Leis Trabalhistas (CLT) se deu em 1a de maio de 1943 por meio do Decreto-Lei n. ${ }^{\circ}$ 5.452, sancionada pelo presidente Getúlio Vargas, foi um marco do ciclo de proteção ao trabalho, a CLT sofreu mais de 370 alterações até chegar à redação que é conhecida atualmente.

Desde sua criação a CLT possui um capitulo exclusivo para proteção do trabalho da mulher. O capitulo III do Art. n. 372 ao Art. n. 401 da CLT intitulado“Da proteção do trabalho da mulher", este tem por objetivo assegurar o livre e permanente acesso da mulher ao mercado de trabalho e principalmente de proteger o trabalho feminino.

Os fundamentos de se requerer um tratamento diferenciado e protetivo a mulher no mercado de trabalho é para atender as diferenças fisiológicas e sociais que as mulheres possuem em relação aos homens (NASCIMENTO 2011). 
A evolução dos direitos do trabalho do gênero feminino foi gradual e demorado até chegar a CLT, o preconceito no âmbito profissional persiste, porém as leis trabalhistas são claras e impõe às cláusulas que devem ser respeitas e o quanto o trabalho do gênero feminino tem valor sem distinção.

\subsection{Evolução do gênero feminino no mercado de trabalho ao longo do tempo}

$\mathrm{Na}$ época colonial no Brasil existiam dois tipos de mulher, a mulher branca que era tida como para casar e a mulher negra (escrava) para trabalhar, porém ambas tinham algo em comum eram tidas comum inferior ao homem, e suas responsabilidades e atividades se limitavam em sua maioria aos cuidados do lar e dos filhos no caso das mulheres brancas e servir o seu senhor no caso das mulheres negras.

Após a independência do Brasil em 1822, o país passa a ser chamado de Império, as mulheres eram totalmente discriminadas, sequer tinham direito ao voto e a maioria analfabeta, os pais tinham suas filhas apenas para casar e depois ter filhos.

As mulheres pobres que não podia se reservar a função de guardiãs do lar enfrentavam o preconceito da sociedade machista de trabalhar em prol do seu sustento e de sua família.

Segundo Calil (2007), devido o final da escravidão com decreto da Lei Áurea em 1888 e a falência do modelo político-econômico da monarquia em 1889, o Brasil torna-se uma República. Neste período há um aumento significativo de mão-de-obra livre, porém devido às péssimas condições de vida dos escravos brasileiros a população ativa possuía um déficit.

O afluxo para as cidades tanto de imigrantes como de ex-escravos acelerou a urbanização das cidades e houve o aumento do número de indústrias. De acordo com o autor acima citado entre os trabalhadores pobres estavam inseridas as mulheres, agora numa sociedade que assumia uma nova identidade, esta mulher que era mal remunerada e recebia cerca de $30 \%$ menos em relação aos homens e ainda tinha que ser chefe de família e enfrentar o preconceito da sociedade.

Os trabalhadores durante a Revolução Industrial eram explorados e com as mulheres era ainda pior, além de mal remuneradas, exerciam suas atividades em condições precárias e eram extremamente desvalorizadas.

Este cenário sofre mudanças significativas com as Guerras Mundiais quando as mulheres tiveram que tomar frente de suas famílias uma vez que seus maridos estavam na guerra deixaram de conduzir apenas as atividades domésticas e assumiram os negócios familiares.

Após o término das Guerras muito chefes de família não voltaram para casa e outros voltaram impossibilitados de exercer as funções que antes eram assumidas por 
eles, desta forma as mulheres definitivamente deixam de serem apenas donas de casa e mães e assumem os trabalhos profissionais. Além de complementar a renda familiar esse ingresso no mercado de trabalho foi muito importante pelas transformações sociais e neste período é aflorada a competência da mulher.

Com a evolução capitalista no século XIX como foi mencionado acima à mão de obra feminina é utilizada fortemente nas plantas fabris e depois de passar por um longo período de exploração algumas leis surgem para regulamentar os direitos dos trabalhadores e algumas focadas na mulher conforme foi descrito no item 2.4 deste trabalho.

Sendo assim, a mulher segue o século XXI mostrando sua capacidade profissional que está cada vez mais requisitada nas empresas e está em constante evolução na sua inserção nas diversas funções no mercado de trabalho, porém ainda existe o preconceito e principalmente a desigualdade salarial exercendo as mesmas funções, que o homem.

\section{Metodologia}

A utilização de métodos científicos é imprescindível para todas as ciências, entretanto os métodos científicos não são utilizados somente pelas ciências e sim por todos os ramos de estudos. Método é a forma admitida para que seja possível atingir o objetivo da pesquisa de forma sistemática e racional, gerando informações com segurança. Conforme Lakatos e Marconi (2010):

Para Karl. R. Popper, o método cientifico parte de um problema (P1), ao qual se oferece uma espécie de solução provisória, uma teoria-tentativa (TT), passando-se depois a criticar a solução, com vista à eliminação do erro (EE) e, tal como no caso da dialética, esse processo se renovaria a si mesmo, dando surgimento a novos problemas (P2) (LAKATOS e MARCONI, 2010, p. 77).

Nesta pesquisa serão utilizados os métodos dedutivo e comparativo. O método dedutivo parte da visão generalizada e a seguir parte para o particular, utilizando-se do que já é conhecido como verdadeiro e é indiscutível, este método é proposto pelos racionalistas como Descartes, Spinoza e Leibniz, os quais acreditam que o conhecimento verdadeiro somente é descoberto pela razão (GIL, 2008).

De acordo com Gil (2008), o método comparativo faz parte dos métodos que indicam os meios técnicos da investigação, que tem como objetivo garantir objetividade e precisão nos estudos sociais para aquele que está fazendo a pesquisa, visando 
orientar para obtenção, processamento e validação dos dados em torno do problema investigado.

$$
\text { Segundo Gil (2008): }
$$

O método comparativo procede pela investigação de indivíduos, classes, fenômenos ou fatos, com vistas a ressaltar as diferenças e similaridades entre eles. Sua ampla utilização nas ciências sociais deve-se ao fato de possibilitar o estudo comparativo de grandes grupamentos sociais, separados pelo espaço e pelo tempo. Assim é que podem ser realizados estudos comparando diferentes culturas ou sistemas políticos. Podem também ser efetivadas pesquisas envolvendo padrões de comportamento familiar ou religioso de épocas diferentes (GIL, 2008, p.16-17).

Além dos métodos citados acima, pode-se dizer que este trabalho trata-se de uma pesquisa descritiva, conforme é abordado por Rampazzo (2002, p.53):

A pesquisa descritiva observa, registra, analisa e correlaciona fatos ou fenômenos (variáveis), sem manipulá-los; estuda fatos e fenômenos do mundo físico e, especialmente, do mundo humano, sem a interferência do pesquisado. [...] o termo "fenômeno" indica apenas um sinônimo para "fato". Entretanto, pode-se estabelecer uma distinção, dizendo-se que "fenômeno" é o fato tal como percebido por alguém. Os fatos acontecem na realidade, independentemente de haver ou não quem os conheça. Mas, quando existe um observador, a percepção que ele tem do fato é que se chama fenômeno. Pessoas diversas podem observar, no mesmo fato, fenômenos diferentes.

Assim sendo, nesta pesquisa foram utilizados dados secundários por meio de pesquisa bibliográfica a livros, artigos científicos, decretos de leis e demais literaturas pertinentes ao tema para dar o embasamento teórico e cientifico necessário sobre os assuntos abordados, além de consultas aos vínculos empregatícios disponíveis na RAIS dos anos de 2010 a 2014 e de tabelas no Sistema IBGE de Recuperação Automática (SIDRA) 2014.

\section{Análise dos resultados}

Neste item serão abordadas as análises realizadas para cumprir com os objetivos gerais e específicos desta pesquisa e confirmar a hipótese do trabalho. A Figura 1 apresentará o número de empregos formais no Paraná e Guarapuava. 
Segundo dados do Ministério do Trabalho e Emprego (MTE), obtidos através da Relação Anual das Informações Sociais (RAIS), foi possível verificar um total de mais de 15 milhões de trabalhadores com vínculo empregatício formal no Paraná e mais de 196 mil em Guarapuava. Conforme é verificado na figura 1, houve uma evolução no número de empregos formais no Estado Paraná no período de 2010 a 2014.

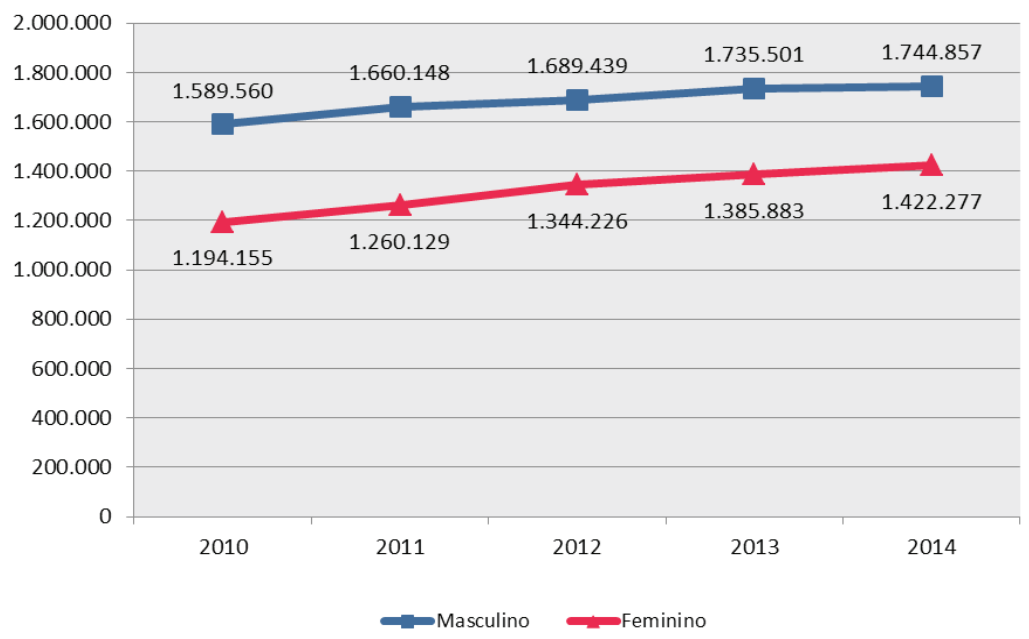

Figura 1 - Evolução do número de emprego formal por gênero, Paraná - 2010 a 2014 Fonte: Adaptada pela autora a partir de dados fornecidos pelo DIEESE/ER-PR - RAIS (2015).

De modo geral no Paraná os vínculos cresceram 13,77\%, para o gênero feminino a variação positiva foi maior do que a ocorrida para todo o Estado correspondendo a 19,10\% enquanto para os homens esta variação foi de 9,77\%.

Outro fato relevante nesta análise é o percentual de representatividade das mulheres no emprego formal do Estado, em 2010 elas eram 42,90\% da mão de obra ocupada e em 2014 este percentual subiu para 44,91\%, houve um crescimento de mais de 200.000 trabalhadoras em um período de cinco anos. Estes dados evidenciam que as mulheres estão deixando a informalidade e estão buscando cada vez mais sua inclusão através de empregos que lhe confiram uma segurança perante a legislação trabalhista.

Em Guarapuava as mulheres correspondiam em 2010 a 37,83\% da força de trabalho e em 2014 houve um crescimento para 40,53\%, estes percentuais correspondem a 13.764 e 17.099 respectivamente. Analisando a variação ocorrida no período de 2010 a 2014 houve um aumento de $24,23 \%$ de trabalhadoras e de $10,92 \%$ de trabalhadores neste período. 
Com base nos dados expostos pode-se concluir que a inserção feminina apesar de estar ocorrendo de forma lenta e gradativa, é um assunto que vem sendo amplamente discutido, e as mulheres mesmo sofrendo dificuldades na inserção em algumas áreas tem-se mostrado forte no seu propósito, visto que possuem o objetivo de melhorar às suas condições de vida e da família, e a realidade atual é outra, pois diversas empresas vêm criando postos de trabalho compatíveis às aptidões femininas, possibilitando cada vez inserção no mercado de trabalho formal.

A figura 2 mostra a distribuição da população feminina e masculina ocupada nos diversos setores de atividade no período analisado no Estado do Paraná. O setor que predomina é o de serviços prestados, contando com mais de 3,8 milhões de trabalhadoras e 3,1 milhões de trabalhadores.
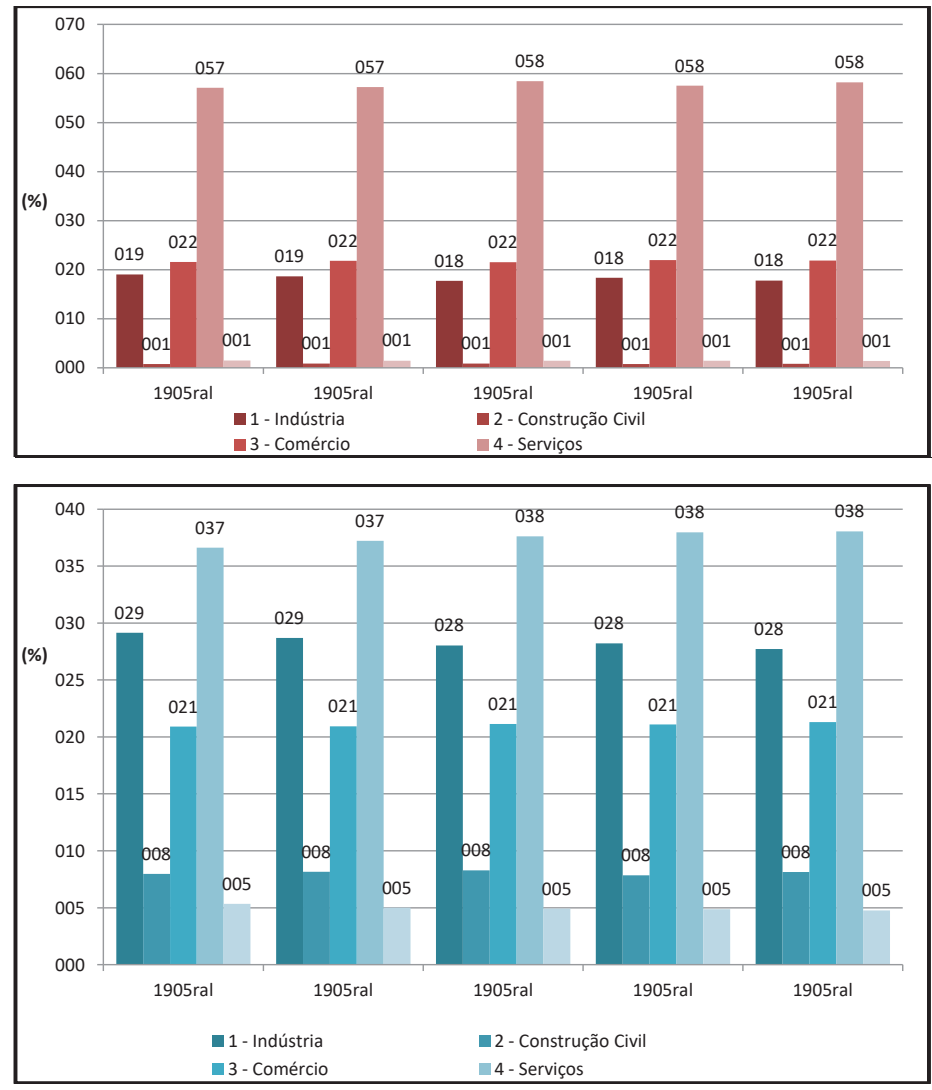

Figura 2 - Composição do emprego formal por gênero, feminino (acima) masculino (abaixo), por grupo de setor, no período 2010 a 2014, no Paraná Fonte: Adaptada pela autora a partir de dados da RAIS (2015). 
Neste contexto no município de Guarapuava, também prevalece os trabalhadores no setor de prestação de serviços nos anos de 2010 a 2014, correspondendo a $38 \%$ dos vínculos do mercado de trabalho formal, onde 41.216 são trabalhadoras e 33.777 são trabalhadores.

No Paraná o segundo setor que mais emprega mulheres é o comércio com 1,4 milhões de trabalhadoras, já para os trabalhadores o comércio é o terceiro setor que mais emprega, porém o número de vínculos é de mais de 1,7 milhões, 19\% superior ao número de vínculos do gênero feminino.

Em Guarapuava o setor do comércio assume a segunda posição para ambos os gêneros, contemplando 24.054 trabalhadoras e 33.085 trabalhadores, a diferença é de $27 \%$ de vínculos formais do gênero masculino em relação ao feminino, totalizando os colaboradores com vínculo formal nos cinco anos analisados (2010 a 2014).

Ainda com base nos dados por setor de atividade é possível verificar as variações que ocorrerem no período de 2010 e 2014 para o gênero feminino, no Paraná e em Guarapuava o setor que obteve a maior variação, ou seja, que absorveu mais mão de obra feminina em 2014 em relação a 2010 foi o setor de construção civil com uma variação positiva de 24,52\% no Paraná (9.370 em 2010 e 11.668 em 2014) e 67,70\% em Guarapuava (96 em 2010 e 161 em 2014).

O setor de construção é tido como predominantemente masculino e tem-se mostrado aberto a inserção das mulheres, segundo uma matéria do Paraná On-line (2015) a empresa MRV Engenharia registrou nos últimos seis anos um aumento de $250 \%$ de inserção de mulheres no seu quadro de funcionários, atribuindo a elas características de muito detalhistas e caprichosas, qualidades estas muito procuradas nos profissionais responsáveis por acabamento das obras.

Os demais setores no Paraná no período analisado, tiveram variações menores, mas todas com tendência de crescimento e que se mostram de relevância no contexto geral, em serviços prestados (21,37\%), comércio (20,51\%), agropecuária $(11,84 \%)$ e na indústria $(11,03 \%)$. Em Guarapuava as variações no período analisado são as seguintes: indústria $(39,17 \%)$, serviços prestados $(26,91 \%)$, comércio $(25,47 \%)$ e a agropecuária teve uma variação negativa $42,77 \%$.

De acordo com a Teoria do Capital Humano, o indivíduo ou as empresas investem em qualificação do profissional e este retorno virá em forma de melhores remunerações e aumento da produtividade para o capitalista que terá seus lucros aumentados.

O maior acesso ao ensino superior, o qual as brasileiras tem tido cada vez mais proximidade, é o principal fator que tem refletido no ingresso das mulheres no mercado de trabalho, e conforme será visto a seguir a escolaridade das mulheres é 
superior a dos homens o que tem possibilitado a constante evolução na inserção da mulher como profissional.

Conforme é possível observar na figura 3, o nível de instrução predominante no mercado de trabalho formal no Paraná é ensino médio completo.
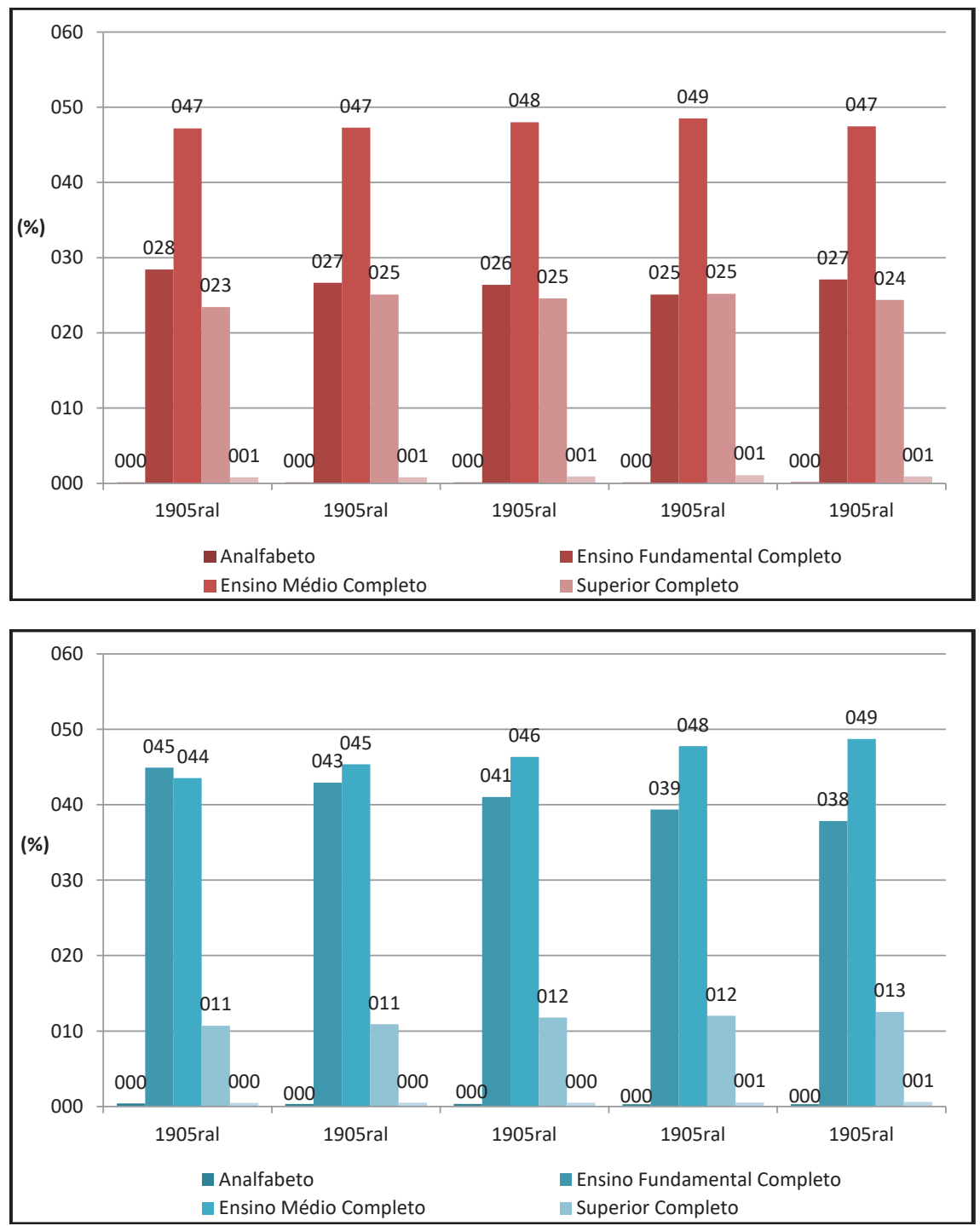

Figura 3 - Composição do emprego formal por gênero, feminino (acima) e masculino (abaixo), no período 2010 a 2014 no Paraná, segundo nível de instrução Fonte: Adaptada pela autora a partir de dados da RAIS (2015). 
Sendo 3,9 milhões de trabalhadores do sexo masculino e 3,1 milhões do sexo feminino. As mulheres se destacam nos trabalhadores que possuem o ensino superior completo, em relação aos homens essa diferença é superior a 64\%, ou seja, as trabalhadoras que possuem ensino superior completo no Paraná totalizam no período analisado 1.610.289 enquanto os homens que atuam no mercado formal com ensino superior são 977.829 .

Um aspecto relevante nesta análise em relação a estes dados mostra que as mulheres além de buscarem constantemente sua inserção no mercado de trabalho, estão investindo em educação superior, almejando melhores cargos e salários.

Em relação ao nível de instrução para Guarapuava, é possível perceber um comportamento diferenciado em relação ao Paraná. A maioria das mulheres inseridas no mercado de trabalho formal possui o ensino médio completo e correspondem a 33.609 trabalhadoras, para os homens o nível de instrução predominante é o ensino fundamental completo e corresponde a 66.408 trabalhadores.

Em relação ao ensino superior completo as mulheres também se destacam em Guarapuava assim como no Paraná, ela são a maioria, as trabalhadoras com vínculo formal chegam a 17.668 e os trabalhadores correspondem ao número de 11.124 representando uma diferença de 59\%. Conforme consta no caderno do IPARDES de Guarapuava (2015), dados de 2013, o município conta com 4 instituições de ensino superior presencial sendo 1 estadual e 3 particulares.

Com esta breve análise, é possível inferir que as mulheres estão buscando se especializar educacionalmente para se inserir no mercado de trabalho, assim como se manter nele e ainda ascender na carreira profissional, onde as empresas tem mostrado uma forte inclinação em contratar mulheres para cargos estratégicos visto que tem obtidos ótimos resultados.

Com base nos dados acima expostos, foi possível perceber uma visível evolução no número de mulheres no mercado de trabalho formal, este crescimento já é considerado uma conquista para um gênero que outrora não tinha direitos algum para se consolidar como profissional, porém os desafios permanecem e entre eles existe um que se destaca fortemente, que é a desigualdade salarial em relação aos homens.

O mercado de trabalho recebe anualmente um número expressivo de mulheres em idade produtiva, tão qualificada quanto os homens, porém a remuneração salarial média mantem-se abaixo, mostrando uma leve reação ano após ano. Conforme consta na figura 4, é possível verificar que houve uma evolução no salário médio no Paraná nos anos de 2010 a 2014. 


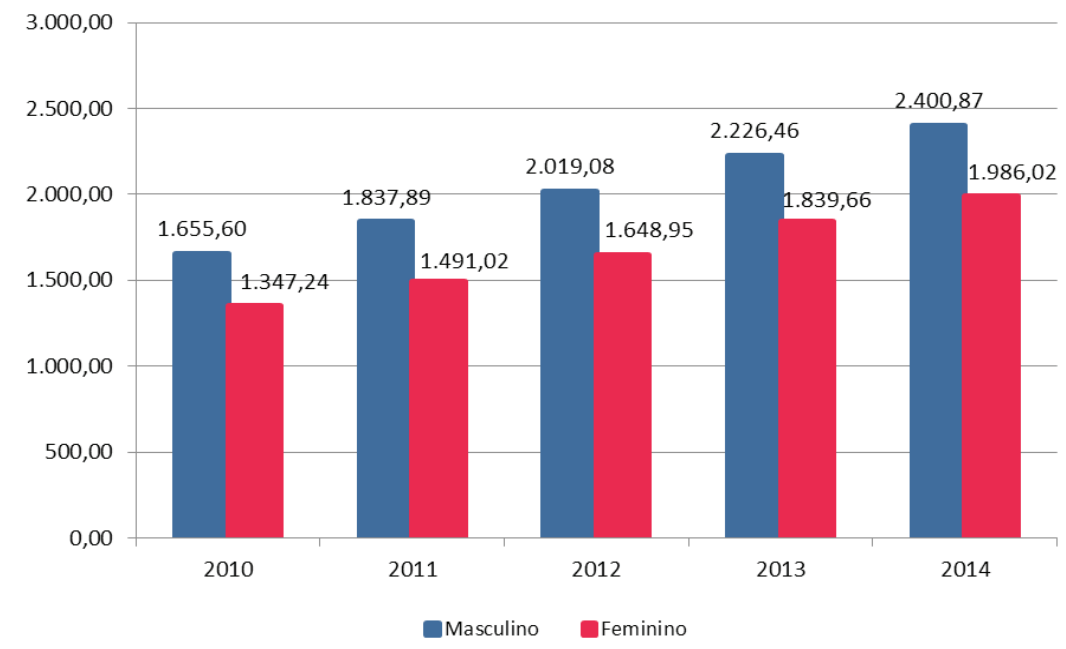

Figura 4 - Evolução do Salário Médio (dez), por gênero, Paraná - 2010 a 2014 Fonte: Adaptada pela autora a partir de dados fornecidos pelo DIEESE/ER-PR - RAIS (2015). Nota: Valores em reais.

Este aumento para as trabalhadoras corresponde a uma variação positiva de $47,41 \%$ e para os trabalhadores de $45,01 \%$. A variação anual em média foi para o gênero feminino de $10,20 \%$ e para o gênero masculino de $9,74 \%$.

No período analisado ainda é possível perceber que as mulheres recebem em média $81,90 \%$ dos salários pagos aos homens. O que se mostra mais divergente é que neste contexto fala-se de um grupo de trabalhadores de mesma faixa etária, no que diz respeito à escolaridade as mulheres estão se especializando mais em relação aos homens e mesmo assim ainda persiste a disparidade salarial. Conforme a figura 5, as trabalhadoras guarapuavanas, assim como no Paraná tiveram uma evolução no salário médio no período pesquisado. 


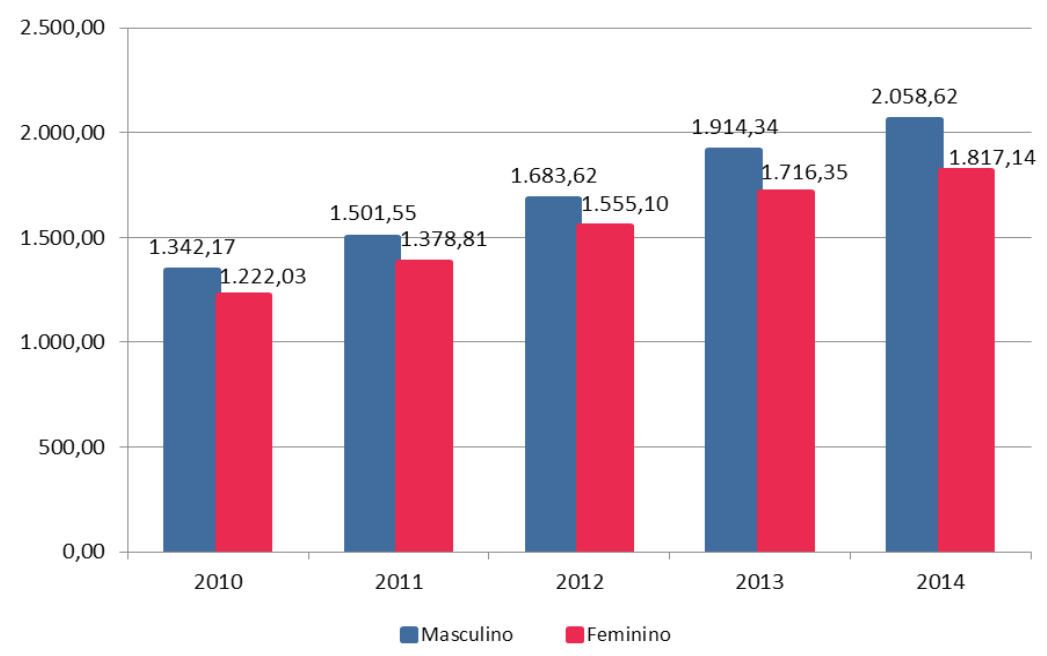

Figura 5 - Evolução do Salário Médio (dez), por gênero, Guarapuava - 2010 a 2014

Fonte: Adaptada pela autora a partir de dados fornecidos pelo DIEESE/ER-PR - RAIS (2015). Nota: Valores em reais.

Esta evolução foi de $48,70 \%$, mas diferentemente do cenário paranaense em Guarapuava os trabalhadores tiveram uma evolução maior neste quesito que foi de $53,38 \%$. A variação anual média para o gênero feminino foi de $10,46 \%$ e para o gênero masculino foi de $11,31 \%$.

Em Guarapuava a diferença entre o salário médio recebido pelas mulheres em relação aos homens no período de 2010 a 2014 é menor se comparada ao do Paraná, às mulheres recebem 90,63\% dos salários pagos aos homens, pode-se atribuir a isto o fato de que os trabalhadores no mercado formal fazem parte, em sua maioria, da mesma faixa salarial.

\section{Considerações finais}

O estudo mostra que houve uma evolução na inserção das mulheres no mercado formal brasileiro, paranaense e guarapuavano, porém a diferença salarial é algo que persiste sem ser explicado de forma clara e objetiva, uma vez que as mulheres possuem maior instrução em relação aos homens.

O Brasil conta com a população em idade ativa em sua maioria feminina, que, ou está desocupada ou estão trabalhando informalmente, fatos estes que deixam de gerar riqueza para a economia do país, as mulheres tem se especializado, se 
escolarizado e estão dispostas a assumir uma vida profissional, porém muitas são as barreiras que são encontradas neste percurso.

O mercado de trabalho tem-se mostrado mais aberto a inserção das mulheres, mas ainda é possível verificar que as mulheres se destacam nas atividades tidas predominantemente femininas, falta por parte do governo à criação de políticas públicas que deem um direcionamento neste campo, que incentive as empresas a absorver a mão de obra feminina nos mais diversos setores e funções.

As mulheres acabam sendo penalizadas no mercado de trabalho por um processo histórico que as manteve incapaz de exercer atividades fora do âmbito doméstico e atualmente mesmo podendo assumir uma carreira, muitas mulheres enfrentam dificuldades em conciliar as atribuições domésticas e profissionais, e este de forma subjetiva acaba sendo um fato direto para que a evolução do gênero feminino no mercado de trabalho não ocorra de forma tão acelerada, quanto às mulheres estão dispostas a entrar no mercado de trabalho.

Este aumento no número de mulheres no mercado de trabalho pode ser explicado por diversos fatores econômicos e sociais, as mulheres buscam cada vez mais independência financeira, atualmente muitas delas são "chefes de família" sendo a principal fonte de renda, outro fator constantemente comentado ao longo do trabalho e que ficou muito evidente nas análises foi o aumento no nível de instrução, as mulheres outrora que não tinham direito sequer de frequentar a escola inicial passaram a ser a maioria dos acadêmicos que concluem o ensino superior e sequem se especializando com pós-graduação, mestrado, doutorado.

Ainda pode ser citado o fato de que esse grau de escolaridade traz intrinsicamente às mulheres juntamente com as questões econômicas uma redução na taxa de fecundidade, e este fato faz com que as mulheres direcionem seu foco para a carreira profissional corroborando para a evolução e inserção delas no mercado de trabalho.

Em síntese, pode-se confirmar a hipótese levantada neste trabalho, pois é verdade que houve uma maior abertura comercial para contratação das mulheres no mercado de trabalho formal, porém elas ainda permanecem exercendo em sua maioria atividades caracterizadas como femininas tendo acesso restrito àquelas tidas como atividades masculinas, é fato que a melhor estruturação das leis trabalhistas voltadas à mulher facilitou a permanência no mercado de trabalho e conciliação da carreira profissional com a vida pessoal, conforme foi exposto nas análises é fato que a maior qualificação também auxiliou na inserção do gênero feminino no mercado de trabalho formal, assim como também possibilitou a muitas mulheres a independência financeira e a melhores condições de vida as famílias destas mulheres. 
O objetivo geral e os específicos, foram todos atingidos, pois foi possível comprovar a evolução da mão de obra feminina no Paraná e em Guarapuava, e ainda foi verificado que nesta análise comparativa há mais similaridade do que diferença, podendo afirmar que Guarapuava segue a mesma tendência do Paraná.

Foi possível verificar que em média nos cinco anos analisados as mulheres representaram 43,93\% e 39,03\% dos vínculos empregatícios do mercado de trabalho formal no Paraná e Guarapuava respectivamente, ainda foi identificado que o grupo de setor que mais admite trabalhadoras é o de prestação de serviço com $57,69 \%$ e 53,54\% em média no período analisado para o Paraná e Guarapuava respectivamente.

O nível de escolaridade das mulheres no Paraná e em Guarapuava que predomina é o ensino médio, em contrapartida para os homens no Paraná a maioria possui o ensino médio e em Guarapuava o nível de instrução que prevalece para eles é o ensino fundamental, porém o destaque é em relação ao percentual de mulheres que concluíram o ensino superior em relação aos homens no período analisado que em média foi de $111 \%$ e 135\%, superior no Paraná e Guarapuava, respectivamente.

E por fim foi evidenciado que a média salarial das mulheres permanece inferior a dos homens como uma regra e no período estudado não foi diferente, elas recebem $81,90 \%$ e $90,63 \%$ dos salários pagos aos homens no Paraná e Guarapuava nesta ordem.

A análise do contexto histórico e dos dados desta pesquisa mostra, que o mercado de trabalho, ainda que seja visto como outro mercado qualquer, onde existe a oferta e a demanda por mão de obra, nele as mulheres ainda estão em um nível abaixo dos homens, e para que exista a tão almejada igualdade em termos de cargos e salários será necessário políticas públicas que visem à inserção das mulheres sem privilégios, mas sim lhes dando o que é de direito, de acordo com suas habilidades, competências e qualificações profissionais.

\section{Nota}

${ }^{1}$ CALIL, Léa E.S. Direito do trabalho da mulher: ontem e hoje.

\section{Referências}

BRASIL, Lei n. ${ }^{\circ}$ 1.596, de 29 de dezembro de 1917. Secretária Geral Parlamentar. Departamento de Documentação e Informação. Reorganiza o Serviço Sanitário do 
Estado. Diário oficial do Estado de São Paulo. São Paulo, SP, 11 de janeiro de 1918. Disponível em: <http://www.al.sp.gov.br/repositorio/legislacao/lei/1917/lei-159629.12.1917.html>. Acessado em 20 de agosto de 2015.

BRASIL, Lei n..$^{\circ}$ 5.452, de $1^{\circ}$ de maio de 1943. Presidência da República. Casa Civil. Subchefia para assuntos jurídicos. Aprova a Consolidação das Leis do Trabalho. Disponível em: <http://www.planalto.gov.br/ccivil_03/decreto-lei/Del5452compilado.htm $>$. Acessado em 20 de agosto de 2015.

BRASIL, Lei n. ${ }^{\circ}$ 9.799, de 26 de maio de 1999. Presidência da República. Casa Civil. Subchefia para assuntos jurídicos. Insere na Consolidação das Leis do Trabalho regras sobre o acesso da mulher ao mercado de trabalho e dá outras providências. Disponível em: <http://www.planalto.gov.br/ccivil_03/LEIS/L9799.htm>. Acessado em 21 de agosto de 2015.

BRÉMOND, Janine; GÉLÉDAN, Alain. Dictionnaire des théories et mécanismes économiques. Paris: Hatier Paris, 1984.

BRUE, Stanley L. História do Pensamento Econômico. 1. Ed. - São Paulo: Cencage Learning, 2011.

CALIL, Léa E.S. Direito do trabalho da mulher: ontem e hoje. Disponível em: $<$ http://www.ambito-juridico.com.br/site/index.php?n_link=revista_artigos_ leitura\&artigo_id=1765>. Acessado em 21 de agosto de 2015.

CALIL, Léa E. S. Direito do trabalho da mulher: a questão da igualdade jurídica ante a desigualdade fática São Paulo, LTr, 2007.

CASARI, Priscila. Segmentação no mercado de trabalho brasileiro: diferenças entre o setor agropecuário e os setores não agropecuários, período de 2004 a 2009. Disponível em:<http://www.teses.usp.br/teses/disponiveis/11/11132/tde-30052012085036/publico/Priscila_Casari.pdf $>$. Acessado em 25 de outubro de 2015.

DATAPREV. Relação de legislação correlata e que altera O DECRETO-LEI No 5.452, DE 01 DE MAIO DE 1943. CONSOLIDAÇÃO DAS LEIS DO TRABALHO CLT.Disponível em: <http://www3.dataprev.gov.br/sislex/paginas/10/1943/ALTERACAOCLT.htm>. Acessado em 25 de outubro de 2015.

FEIJÓ, Ricardo. História do Pensamento econômico. 2. Ed. - São Paulo: Atlas, 2007. 
GIL, Antônio Carlos. Métodos e técnicas de pesquisa social. $6^{\mathrm{a}}$ ed. - São Paulo: Atlas, 2008.

HUNT, E.K. História do Pensamento Econômico. $7^{\text {a }}$ Ed. - Rio de Janeiro: Campus, 1981.

KELNIAR, Vanessa C.; LOPES Janete L.; PONTILI Rosangela M. A Teoria do Capital Humano: Revisitando Conceitos. Disponível em <http://www.fecilcam.br/nupem/ anais_viii_epct/PDF/TRABALHOS-COMPLETO/Anais-CSA/ECONOMICAS/05-Vckelniartrabalhocompleto.pdf $>$. Acessado em 24 de outubro de 2015.

KEYNES, John M. A Teoria Geral do Emprego, do Juro e da Moeda. Edição traduzida. São Paulo: Editora Nova Cultural, 1996.

LAKATOS, Eva M.; MARCONI Marina A. Fundamentos de Metodologia Cientifica. $7^{\text {a }}$. Ed. - São Paulo: Atlas, 2010.

LIMA, Ricardo. Mercado de trabalho: o capital humano e a teoria da segmentação. Disponível em: <http://ppe.ipea.gov.br/index.php/ppe/article/viewFile/497/439>. Acessado em 23 de outubro de 2014

MARX, Karl. O Capital: Crítica da Economia Política. Edição traduzida. São Paulo: Editora Nova Cultural, 1996.

MINISTÉRIO DO TRABALHO E EMPREGO (MTE). Relação anual de Informações sociais - RAIS, 2015.

NASCIMENTO, Amauri, Nascimento do. Curso de Direito do Trabalho. 26a Ed. São Paulo: Editora Saraiva, 2011.

PARANÁ ONLINE TRIBUNA. Mão de obra feminina aumenta $250 \%$ no setor da construção civil. Disponível em: http://www.parana-online.com.br/editoria/econo$\mathrm{mia} /$ news $/ 881164 /$ ?noticia $=\mathrm{MAO}+\mathrm{DE}+\mathrm{OBRA}+\mathrm{FEMININA}+\mathrm{AUMENTA}+250+\mathrm{NO}$ +SETOR+DA+CONSTRUCAO+CIVIL. Acessado em 06 de dezembro de 2015.

RAMPAZZO, Lino. Metodologia Cientifica: para alunos dos cursos de graduação e pós-graduação. $3^{\text {a }}$ Ed. - Editora Loyola. 2002.

RICARDO, David. Princípios de Economia Política E Tributação. Edição traduzida. São Paulo: Editora Nova Cultural, 1996. 
SINGER, Paul Israel. Economia política do trabalho: elementos para uma análise histórico-estrutural do emprego e da força de trabalho no desenvolvimento capitalista. São Paulo: Hucitec, 1979.

SMITH, Adam. A Riqueza das Nações: Investigação Sobre sua Natureza e suas Causas. Edição traduzida. São Paulo: Editora Nova Cultural, 1996.

SOUZA, Maria Cristina Cacciamali de. Mercado de trabalho: abordagens duais. Rev. adm. empres., São Paulo, v. 18, n. 1, p. 59-69, Mar. 1978. 